DOI: $10.20472 /$ IAC.2017.031.052

\author{
JUTHARAT SUNPRASERT \\ King Mongkut's University of Technology Thonburi, Thailand \\ EKAPONG HIRUNSIRISAWAT \\ King Mongkut's University of Technology Thonburi, Thailand \\ NARONGRIT WARAPORN \\ King Mongkut's University of Technology Thonburi, Thailand \\ SOMPORN PEANSUKMANEE \\ King Mongkut's University of Technology Thonburi, Thailand
}

\title{
METAL SHIP AND ROBOTIC CAR: A HANDS-ON ACTIVITY TO DEVELOP SCIENTIFIC AND ENGINEERING SKILLS FOR HIGH SCHOOL STUDENTS
}

\begin{abstract}
:
Metal Ship and Robotic Car is one of the hands-on activities in the course, the Fundamental of Engineering that can be divided into three parts. The first part, the metal ships, was made by using engineering drawings, physics and mathematics knowledge. The second part is where the students learned how to construct a robotic car and control it using computer programming. In the last part, the students had to combine the workings of these two objects in the final testing. This aim of study was to investigate the effectiveness of hands-on activity by integrating Science, Technology, Engineering and Mathematics (STEM) concepts to develop scientific and engineering skills. The results showed that the majority of students felt this hands-on activity lead to an increased confidence level in the integration of STEM. Moreover, $48 \%$ of all students engaged well with the STEM concepts. Students could obtain the knowledge of STEM through hands-on activities with the topics science and mathematics, engineering drawing, engineering workshop and computer programming; most students agree and strongly agree with this learning process. This indicated that the hands-on activity: "Metal Ship and Robotic Car" is a useful tool to integrate each aspect of STEM. Furthermore, hands-on activities positively influence a student's interest which leads to increased learning achievement and also in developing scientific and engineering skills.
\end{abstract}

\section{Keywords:}

Hands-on activity, STEM education, Computer programming, Metal work 


\section{INTRODUCTION}

Learning by doing is a way to help students develop an understanding of subjects and their learning skills through the process of interaction with objects and environments whilst doing a task (Klahr, Triona and Williams, 2007: 183). Among the various ways of learning by doing, hands-on learning benefits students through a real-life experience. This can foster learning, thinking and practical skills in learners through exploration, experimentation, and problem solving, etc. (Rolston and Cox, 2015: 261). For these reasons, hands-on learning is an enjoyable and effective form of learning. In the integrated learning of STEM, hands-on learning is often selected as a way to engage students to effectively learn several topics and skills (National Research Council, 2011). It seems that the learning style which combines STEM with hands-on activity is widely acceptable in the classroom of the $21^{\text {st }}$ century (Christensen, Knezek and Tyler-Wood, 2015: 898).

As a high school organized by Engineering Science Classroom (ESC) of King Mongkut's University of Technology Thonburi (KMUTT), its curriculum focuses not only on basic knowledge for high school students, but also on developing hands-on skills to nurture young researchers in engineering and technology. The integrated curriculum was designed under the concept of what is called "Story Based Learning". Through this approach, the contents are taught as "stories", which arranges the contents of all subjects in chronological order of humankind's history. Furthermore, various hands-on activities are provided in this curriculum for developing skills of thinking, learning and making things. Importantly, the hands-on activities focus on the integration of Science, Technology, Engineering and Mathematics (STEM) and Arts. Another goal of these activities is to help students understand how to apply knowledge in real contexts and to develop a learning environment suitable for students (Christensen, Knezek and Tyler-Wood, 2015: 898).

In the course, the Fundamental of Engineering II, $10^{\text {th }}$ Grade school students get the chance to do a hands-on activity called "The Metal Ship and Robotic Car". This activity can be an embodiment of the successful hands-on STEM-based education in the school. This integrates several contents in STEM such as force equilibrium and center of mass in physics (science), vector and basic geometry (mathematics), basic engineering drawing (engineering), programming and robotics (technology), etc. The activity engages students and allows them to identify issues and design their own solutions.

"The Metal Ship and Robotic Car" aims to create an opportunity for interactive learning which is divided into two major sections. Firstly, students learn how they can apply mathematics and physics to design and make the prototype of a metal ship. Secondly, students learn how to apply programming to make a robotic car. Therefore, this research has focused on the effectiveness of hands-on activity with integrating STEM concepts to develop scientific and engineering skills. 


\section{OBJECTIVE}

1. To investigate the effectiveness of STEM learning and teaching through hands-on activity

2. To determine the effect of integrating the robotics activity on learning programming

3. To develop metal ship and robotic car activity on STEM-based learning in a coherent way

\section{METHODOLOGY}

\section{A. Learning Design}

In the previous semester, students were trained to do isometric and orthographic drawings. The purposes were to let students understand and realize the importance of engineering drawing and to apply two-dimensional, three-dimensional drawing methods to various objects (Rolston and Cox, 2015: 261). Consequently, students could apply the previously learned skills of engineering drawings in the design. In the second semester of $10^{\text {th }}$ Grade, the students were assigned to design and make a metal ship, as well as do the program coding for controlling a robotic car in the course, as mentioned above. The students then had to combine the workings of these two objects in final testing as a summative evaluation of the course. Finally, teachers discussed and concluded about the activity. Later, students were asked to complete a questionnaire to share their thoughts. The learning process included each activity and concept of STEM, as shown below in Figure. 1:

\section{Figure 1: Learning Process}

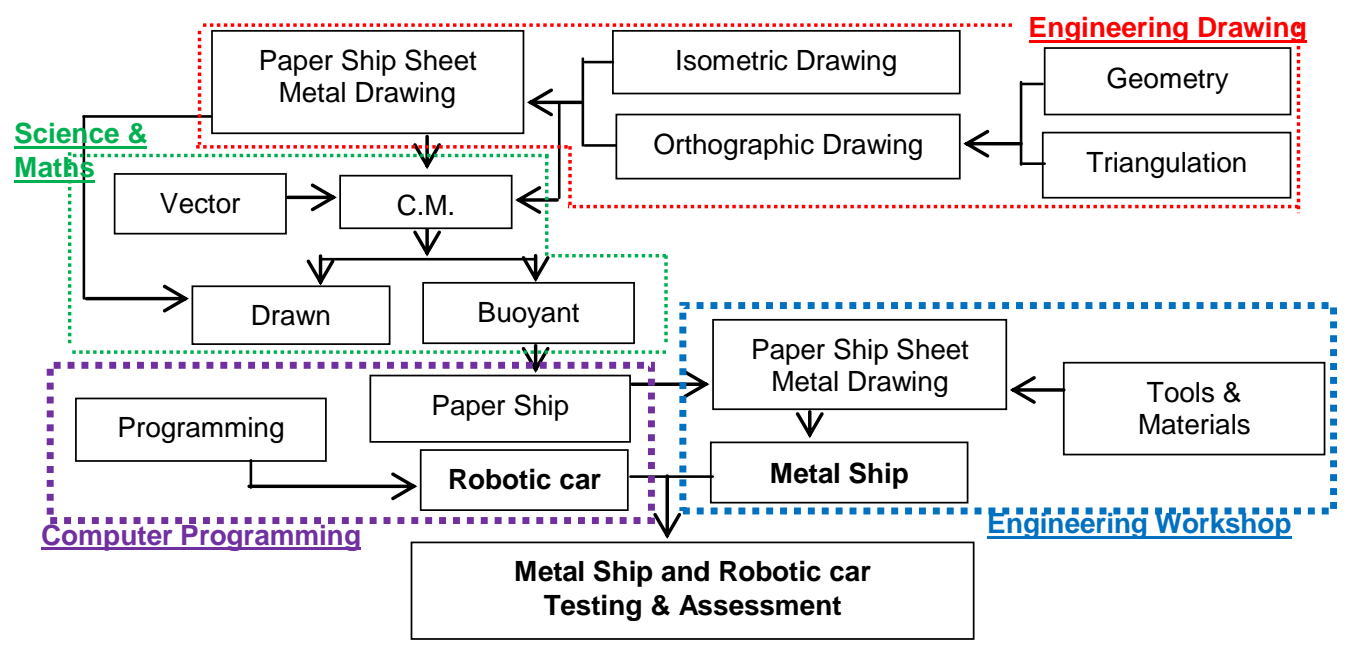

\section{B. Participant}

The participants in this research were $2510^{\text {th }}$ Grade high school students consisting of 8 males and 17 females. The students were divided into eight groups of three to four members each. 


\section{Hands-on Activities}

\section{1. "Metal Ship" Activity}

After the formation of groups, the first activity, "Metal Ship" was carried out. The purpose of the activity was to allow the students demonstrate STEM concepts.

\subsection{Basic Engineering Drawing}

Students have studied basic engineering drawing in the course of the Fundamental of Engineering I \& II since $10^{\text {th }}$ Grade. This subject covers the basics of 2-D and 3-D drawing. These topics and activity were sequenced in logical in order to develop spatial visualization (Sorby and Baartmans, 2000: 301). The topical outline for the Fundamental of Engineering I \& II course is as follows:

(1) Students started to learn geometric construction, isometric and orthographic drawing. The purpose of these topics was to be able to conceive what an object would look like from different perspectives.

(2) Students learned orthographic drawings and applications. Objects with inclined surfaces were demonstrated and orthographic and isometric drawings were made of these objects.

(3) Students were instructed on how to create sheet metal drawing, which were the method of folding the given 2-D pattern.

(4) Students were introduced to a sheet metal application which could be folded into 3-D shapes and studied. The students were also asked to complete the task of building a "Paper Ship" that contains unique animal characteristics. The purposes of paper ship construction were to demonstrate ship paper prototype by testing, as a fitting for each part and connections, and engaged students to create a paper ship and use creative thinking.

(5) Students were asked to demonstrate whether their designed ship was buoyant before welding the metal ship, with the consideration of center of mass (CM) by calculating vector quantity from the paper ship's sheet metal drawing and orthographic drawing.

(6) Students learned to use several tools of metalwork and learned about the restriction of each kind of metal and to connect pieces of metal by welding. Then, they created a metal ship's sheet metal drawing.

(7) Students welded the metal ship at the Industrial Engineering Workshop, which covered understanding about the physical materials and can construct models with the appropriate choice of materials.

\subsection{Science}

Many concepts in physics are deemed complex and difficult for students. Hands-on activity has been responded positively for conveying concepts in physics and being a 
great way to engage students in learning (Wangdi, Dorji and Dema, 2015: 147). Teaching activities were as follows:

(1) Teacher asked students about the concept of averaging a quantity, and then gave them examples of averaging several quantities, such as the height of students in the room. Next, the students were taught about the definition of the center of mass (CM), and related this with the concept of averaging. Namely, that CM can be thought of as the averaging of position vectors with the mass as the weight of averaging.

(2) Students were given the exercise to calculate the $\mathrm{CM}$ of the system consisting of two point-masses, three point-masses and an arbitrary number of point-masses.

(3) Then, students were challenged to calculate the CM of a 2-D plate of different geometrical shapes, e.g. rectangular, triangle and circle, with uniform area density. Next, the students were taught to calculate the $\mathrm{CM}$ of the system of many plates by changing the problem of plates to the problem of points. In other words, students learned the concept of representing an object of arbitrary shape of mass $M$ with a point-mass of mass $\mathrm{M}$ at the $\mathrm{CM}$ in the calculation of the $\mathrm{CM}$ of the system of many objects.

(4) The teacher allowed students discussed within their group how to calculate the $\mathrm{CM}$ of the ship from their orthographic drawings and sheet metal drawing. The teacher then asked them to show their chosen methods, and also asked them about the pros and cons of each method. Next, the teacher gave an example of a simple object with orthographic drawings and sheet metal drawings, and discussed how to calculate the $\mathrm{CM}$ of this example together with students to clarify the pros and cons offered by each group again. However, the teacher did not conclude which method was the best one. The students were free to choose the method of calculation themselves in each group.

\subsection{Mathematics}

Mathematics is used as a tool to solve problem. This activity required not only understanding mathematical concepts but also critical thinking, numeracy skill beyond computation. Teaching activities were as follows.

(1) Teacher explained how to create orthographic and advances to create sheet metal drawing. The purpose and application of the items must be understood in order to acquire skills in "geometric thinking".

(2) Teacher explained and compared complex objects such as inclined surface that could not be seen in its true shape in principal view. Students learned how to find true length for complex objects by using triangulation to solve problem.

(3) In teaching about the center of mass, students practiced the skills of vector addition during the calculation of the center of mass of their design. Also, they sometimes needed to apply scalar product and cross product of vectors. 


\subsection{Engineering Workshop}

Prior to activity, students in each group created a sheet metal drawing of a ship, calculated $\mathrm{CM}$ and built the paper ship prototype. Then the teacher demonstrated for students how to study the principle of sheet metal working and its fabrication in the workshop with topics on safety in the workshop, metal hand tools and fabrication machine, sheet metal materials, cutting and forming method, welding and soldering.

Then each group discussed their pattern design drawing and fabrication technique with their teacher. The teacher gave them the modification for their ship design to make a feasible concept in tune with the practical workshop period. After they trained, each group fabricated their own ship under the supervision of the teacher and his assistant. After the ships had been developed, the teacher took each ship to inspect the quality and scored them based on workmanship and teamwork, technique and difficulty, problem solving attitude and product quality.

\section{2. "Robotic car" Activity}

The purpose of using robots in class was to allow students apply the knowledge and skills of programming into tangible problems. Comparing the learning session on problem solving over programming language without a tangible kit in the past, the students felt more excited during the time they adjusted their programs to control the robot under the environmental constraints. Four components were used during the robotic car activities:

(1) Robotic toolkits allowing the students to comprise board of microcontroller with sensors, switches, LED light bulbs, and battery as a vehicle of their design. The motor was added in order to control the wheels for movement.

(2) Sensors enabling students to detect the environment surrounding the robot. Examples of sensors are brightness detector, light reflection detector using infrared and touch-base detector. Students gained more confidence on the computational problem solving after applying their own logic via the automatic input from sensors.

(3) Drag-and-drop programming language enhancing the students' ability to apply their programming skills on Python learning from the previous semester with a nontedious and less error-prone programming style. Students could concentrate more on problem solving rather than syntactical concerns.

(4) Environment creation under the designed scenario allowing students to create a breakthrough solution for their unusual problem. Having the freedom of choosing their own problem scenario boosted the students' enjoyment of the class assignments, especially when creativity on art and tangible display were blended into the problem.

The students learned basic programming using Python language for coding in the first semester. With robotics programming learning, the teachers developed the scientific technology skills of the students in the following six steps during the second semester.

(1) Introduction to Embedded System The students were shown how to apply programming skills into the Internet of Things (IoT). Learning programming will be 
necessary as a part of the enterprise software application (Selinger, Sepulveda and Buchan, 2013). Devices attached to people can be applied with software which leads to intelligent devices.

(2) Introduction to the robot Teachers started by showing the students the programmable robots. Showing the final outcome of project to the students before learning the necessary knowledge can draw out the enthusiasm from the students about the prospect of their ability (Eguchi, 2014: 27).

(3) Applying programming for robotics control Sensors were the key success of tangible learning. Students learnt how to add sensors to a robot with a drag-and-drop controlling program. Basic knowledge of programming such as assignment, decision, and loop was applied with the robot and its detachable sensors (Eguchi, 2014: 27).

(4) Problem solving Due to the movement requirement of the robotic problem, students must analyze the movement problems. They must logically create a programming solution over the sensors so that the robot can move according to the problem scenario.

(5) Integrated intelligent robot At the end of semester, the students were assigned a project for a real world problem. The students had to propose a real world problem to be solved by the robot such as an auto-drive car on the road, an automatic waitress at a restaurant. The students had to assemble robots with multiple sensors, wheels, motor, etc., at the accurate position in order to solve their problem (Eguchi, 2014:27).

(6) Creative thinking on environment Students must imagine the new environment of the place applying their robot. Artworks were required from the team members. Students have to realize that without attractive display during the demonstration, customers will not be impressed by their product.

\section{Metal Ship and Robotic Car Test Activity}

Test procedures consisted of how the robotic car was able to move between black lines, including strength and turning right on the way, together with pushing the metal ship and stopping on the final black line. Then, the metal ship was to slide on inclined surface into a water-filled bucket and remain afloat for one minute. The metal ship and robotic car test procedure is shown in Figure 2. The purpose for linking these two activities was to allow students to approach the concept of human-computer interaction and respond positively in STEM learning. 
Figure 2: Metal Ship and Robotic Car Test Procedure

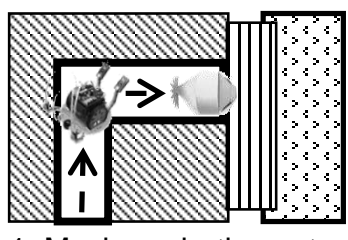

1. Moving robotic car to metal ship

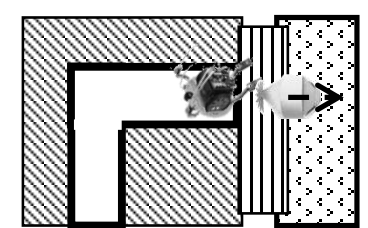

2. Pushing metal ship to water bucket

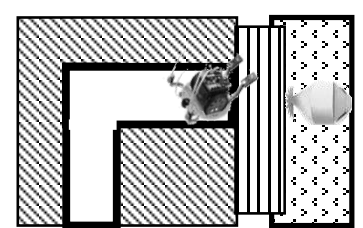

3. Buoyant metal ship for 1 minute

\section{Assessment}

Methods of assessment include the observation of students' performance, students' knowledge in assessment questionnaire, as well as self-assessment. The students' assessment questionnaire was administered to investigate the level of enhancement of the students' knowledge after activities. There were three activities that were designed to help students' understand the concept of STEM. A total of three openended questions were used in the questionnaire and answered based on their confidence using a 5-point Likert scale: $1=$ not confident, $2=$ hardly confident, $3=$ somewhat confident, $4=$ confident, $5=$ very confident. For self-assessment, the students evaluated their own progress or success in the learning process using the following 5-point Likert scale: 1 = strongly disagree, 2 = disagree, 3 = undecided, $4=$ agree, 5 = strongly agree (Klahr, Triona and Williams, 2007: 183).

\section{RESULT AND DISCUSSION}

Before the students constructed the metal ship and assembled the robotic car, they completed a knowledge assessment questionnaire. After the metal ship and robotic car had been combined and tested, a nearly identical knowledge assessment questionnaire was also administered. Analysis of Variance (ANOVA) was used to analyze the collected data. Values were considered at $95 \%$ significant $(p<0.05)$ and a statistical program was used to perform the calculation as follows: 1) pretest and posttest score of self-assessment on the students' knowledge, and 2) the student selfassessment in each aspect of STEM through hands-on activity.

A knowledge assessment questionnaire (Klahr, Triona and Williams, 2007: 183) was used to measure changes in students' level of knowledge regarding the integration of STEM. Questions one through three on the pre- and posttest versions of the questionnaire were identical open-ended questions asking about the benefits of learning in the course of the Fundamental of Engineering II, the understanding of STEM concept by using a hands-on activity and the integrating in each aspect of STEM together with experiential learning in hands-on activity. In addition, after responding to each question, students indicated their confidence in their answer on a 5 -point scale. 
TABLE 1: Pretest and posttest score of self-assessment questionnaire on students' knowledge

\begin{tabular}{lcccc}
\hline \hline Test & Mean \pm SD & Median & $\mathrm{N}$ & p-value \\
\hline Pretest & $2.25 \pm 0.76^{\mathrm{b}}$ & 2 & 25 & \multirow{2}{*}{$0.000^{\star}$} \\
Posttest & $3.64 \pm 1.03^{\mathrm{a}}$ & 4 & 25 & \\
\hline \hline
\end{tabular}

* Values followed by the same letter in the same column are not significantly different $(P>0.05)$

As shown in Table 1, one way (factor) ANOVA revealed a statistically significant difference between the mean score of pretest $(M=2.25, S D=0.76)$ and posttest $(M=3.64, S D=1.03)$ at the $p$-value of $0.000(<0.05)$. The posttest score of students' levels of knowledge as summarized in Table 1 were quite positive. The majority of students felt this hands-on activity allowed them to increase their level of confidence in the integration of STEM from the $2^{\text {nd }}$ level (hardly confident) in pretest to $4^{\text {th }}$ level (confident) in posttest. Moreover, students felt more productive, interested and enthusiastic (Holstermann, Grube and B geholz, 2010: 734). Moreover, one openended question was designed to assess the integration of the students' knowledge. Their answers were classified as "excellent answer" and "good answer" if they could draw a flow diagram completely or near completely answer, which connected all of the knowledge compared to the teacher's learning processes. However, if students provided a somewhat correct and an incorrect answer, they were classified as "fair answer" and "poor answer", respectively.

TABLE 2: The percentage of student in each answer classification

\begin{tabular}{cccc}
\hline \hline Excellent & Good & Fair & Poor \\
\hline $24 \%$ & $24 \%$ & $24 \%$ & $28 \%$ \\
\hline \hline
\end{tabular}

The classification of the answer in Table 2 showed that $48 \%$ of all students engaged well with the STEM concepts. They were able to understand the "metal ship" and "robotic car" activity as a tool to integrate each aspect of STEM.

TABLE 3: Student self-assessment score in each aspect of STEM

\begin{tabular}{lccc}
\hline \multicolumn{1}{c}{ STEM concept } & Mean \pm SD & Median & N \\
\hline Science \& Mathematics & $4.08 \pm 0.55$ & 4 & 25 \\
Engineering Drawing & $4.44 \pm 0.51$ & 5 & 25 \\
Engineering Workshop & $4.34 \pm 0.62$ & 4 & 25 \\
Computer Programming & $3.86 \pm 0.69$ & 4 & 25 \\
\hline \hline
\end{tabular}


The self-assessment part of the questionnaire was to investigate how students managed the hands-on activities. The aims of the self-assessment questionnaire were what students learn in the way of the hands-on activity (see Figure 1). The questionnaire was divided into 4 parts, and each part consisted of science and mathematics, engineering including basic drawing and workshop and computer programming.

From the results, shown in Table 3, for each part the students were able to obtain the knowledge of STEM through hands-on activities, since the mean score for science \& mathematics, engineering drawing, engineering workshop and computer programming was $4.08,4.44,4.34$ and 3.86 , respectively. Furthermore, the median value indicates that most students felt they agree and strongly agree with the learning process.

\section{CONCLUSION AND FURTHER STUDIES}

The Fundamental of Engineering I \& II course aims to nurture engineering skill in students. The integration of hands-on activities in the course of the Fundamental of Engineering is a key for effective STEM instruction. The majority of students felt this hands-on activity allowed them to increase their confidence levels in the integration of STEM. The results of this study showed that the mean scores of the self-assessment questionnaire on students' knowledge posttest were significantly higher than the mean scores of pretest. This indicates that hands-on activity: "Metal Ship and Robotic Car" as a great tool to integrate each aspect of STEM. Furthermore, hands-on activities positively influence the student's interesting, which leads to greater learning achievement, and also developing scientific and engineering skills.

For a further study, the Fundamental of Engineering course instructors plan to keep these hands-on activities in the course in each year and connecting between these hands-on activities should be implemented. Moreover, incorporating this learning process into the course will provide students with the knowledge and skills to become scientists and engineers in the future.

\section{ACKNOWLEDGMENTS}

The curriculum had been improved and developed by many staffs of KMUTT. The Metal Ship and Robotic Car project was also initiated in developing the curriculum. We would like to express our sincere gratitude to all of them. The study has been supported by the Office of Engineering Science Classroom (ESC) which organizes the Darunsikkhalai Science School (SciUS program) or DSS. We are grateful to ESC for the financial support in attending this conference 


\section{REFERENCES}

Christensen, R.; Knezek, G. and Tyler-Wood, T. (2015) J.Sci. Educ Technol. Alignment of Hands-on STEM Engagement Activities with Positive STEM Dispositions in Secondary School Students. 2015, vol. 24, pp. 898-909.

Eguchi, A. (2014) Proceedings of $4^{\text {th }}$ International Workshop Teaching Robotics, Teaching with Robotics \& $5^{\text {th }}$ International Conference Robotics in Education. Robotics as a Learning Tool for Educational Transformation. 2014, pp. 27-34.

Holstermann, N.; Grube D. and Bögeholz, S. (2010) Res Sci Educ. Hands-on Activities and Their Influence on Students' Interest. 2010, vol. 40, pp. 734-757.

Klahr, D.;Triona L. M. and Williams, C. (2007) Journal of Research in Science Teaching. Hands on What? The Relative Effictiveness of Physical Versus Virtual Materials in an Engineering Design Project by Middle School Children. 2007, vol. 44, no. 1, pp 183-203.

National Research Council, (2011) National Academies Press. Successful K-12 STEM education: Identifying effective approaches in science, technology, engineering, and mathematics. 2011, Washington, D.C.

Rolston, J.S. and Cox, E. (2015) Springer International Publishing Swizerland. Engineering for the Real World: Diversity, Innovation and Hands-on Learning. 2015, pp. 261-278.

Selinger, M.; Sepulveda A. and Buchan J. (2013) CISCO. Education and the Internet of Everything: How Ubiquitous Connectedness Can Help Transform Pedagogy, 2013.

Sorby, S.A. and Baartmans, B.J. (2000) Journal of Engineering Education. The Development and Assessment of a Course for Enhancing the 3-D Spatial Visualization Skills of First Year Engineering Students. 2000, pp. 301-307.

Wangdi, D.; Dorji, K. and Dema, M. (2015) Proceedings of the $2^{\text {nd }}$ International Conference on Innovation in Education Thailand. Hands-on Activity to Enhance Middle Secondary Students' Understanding about Relation of Mass, Volume and Density of Objects Using 5e Learning Model. 2015, pp.147-155. 